\title{
PRINCÍPIO DA COOPERAÇÃO: DO CONFLITO À SOLUÇÃO CONSENSUAL DOS CONFLITOS $^{1}$
}

\author{
Ana Paula Gonçalves da Silva ${ }^{2}$ \\ Frederico de Andrade Gabrich ${ }^{3}$
}

\section{RESUMO}

O trabalho científico tem o objetivo realizar análise do princípio da cooperação, apresentado no Código de Processo Civil como norma fundamental e meio para efetivação do direito constitucional à duração razoável do processo e para a pacificação social. São analisados a eficácia do princípio em uma cultura jurídica de litigiosidade e a sua importância para a solução do problema de pesquisa: como promover a solução mais eficiente da solução dos conflitos em um ambiente marcadamente litigioso. Utilizou-se pesquisa bibliográfica, o método hipotético dedutivo, tendo como marcos teóricos o processo constitucional democrático e a análise estratégica do Direito.

Palavras-chave: Princípio da cooperação; litigiosidade; mediação; conciliação; arbitragem.

\section{PRINCIPLE OF COOPERATION: FROM CONFLICT TO THE CONSENSUAL SOLUTION OF CONFLICTS}

\begin{abstract}
The objective of the study is to analyze the principle of cooperation, fundamental norm of the Civil Procedure Code and a way to implement the constitutional right to a reasonable duration of the process and a social pacification. The text discusses the effectiveness of the principle in a culture of litigation and its importance for the solution of the research problem: how to promote the most efficient resolution of conflicts in a markedly litigious environment. It was used a bibliographic research, the hypothetical deductive method, having as theoretical frameworks the democratic constitutional process and the strategic analysis of the Law.
\end{abstract}

Keywords: Principle of cooperation; litigiousness; mediation; conciliation; arbitration.

\section{Introdução}

Este trabalho científico tem o objetivo realizar breve análise do princípio processual da cooperação.

Em uma visão tradicional do processo, ainda que pouca adequada ao modelo do Estado Democrático de Direito e ao princípio do devido processo legal, inserto no texto constitucional (BRASIL, 1988), as partes ora atuam como se estivessem em uma disputa, na

\footnotetext{
${ }^{1}$ Os autores agradecem o apoio recebido da Universidade FUMEC e do CNPQ, para realização da pesquisa denominada A Regulação de Arbitragem em Documentos Societários como Método Alternativo para Resolução de Problemas entre Sócios.

${ }^{2}$ Mestranda do PPGD da Universidade FUMEC.

${ }^{3}$ Professor Adjunto da Universidade FUMEC. Especialista, Mestre e Doutor em Direito pela UFMG.
} 
qual uma tenta neutralizar os argumentos e provas apresentados pela outra, ora se veem premidas a atender ao que o magistrado determinar para a solução da lide.

Parece pouco provável, assim, que adotem uma atitude cooperativa. Por outro lado, a norma processual civil brasileira em vigor (BRASIL, 2015) não apresenta uma definição para o que venha a ser "cooperação", limitando-se a informar seu desiderato, que é a obtenção em tempo razoável de uma solução de mérito justa e eficaz.

Nesse contexto, faz-se necessária a investigação científica dos limites do princípio da cooperação, e sua aplicação no processo civil.

E este revela-se assunto de grande relevância, especialmente quando se tem em conta o direito constitucional que os litigantes têm à razoável duração do processo, bem como a necessidade de ser obtida a efetiva pacificação social para os conflitos, quando eles surgem na sociedade, normalmente em decorrência de uma falha do planejamento jurídico estratégico adotado pelas partes para a consecução dos seus objetivos.

Para esse artigo, parte-se da ideia do conflito como a base do processo judicial, do princípio da cooperação explicitado pelo Código de Processo Civil, e chega-se à análise da possibilidade de aplicação desse último também aos meios consensuais de solução das controvérsias. Por isso, pode-se dizer que o problema de pesquisa é como promover a solução mais eficiente da solução dos conflitos em um ambiente marcadamente belicoso e litigioso?

Tudo isso com uso pesquisa e análise de bibliográfica, bem como do método hipotético dedutivo, utilizando-se como marcos teóricos o processo constitucional democrático e a análise estratégica do Direito.

\section{O conflito como a base sociológica do processo judicial e o princípio da cooperação}

A Constituição Federal, em seu artigo, 5, LXXVIII, diz que "a todos, no âmbito judicial e administrativo, são assegurados a razoável duração do processo e os meios que garantam a celeridade de sua tramitação". (BRASIL, 1988).

É previsto o princípio da razoável duração do processo também no Código de Processo Civil (CPC), tendo sido determinado no seu artigo $6^{\circ}$, no capítulo destinado às normas fundamentais, que "todos os sujeitos do processo devem cooperar entre si para que se obtenha, em tempo razoável, decisão de mérito justa e efetiva.” (BRASIL, 2015). 
A presença de princípios constitucionais na lei ordinária é proposital, com vistas a tornar o sistema jurídico harmônico, como é informado na exposição de motivos do Anteprojeto do Novo Código de Processo Civil (SENADO, 2010).

Portanto, pela expressão dos ditames constitucionais no processo civil, tem-se que as partes litigantes devem agir de modo a possibilitar não apenas que a decisão de mérito seja alcançada em tempo razoável, mas também que ela seja qualitativamente superior, por apresentar efetividade, eficácia e justiça.

Mas o que se deve entender por cooperação? Seria a norma uma determinação para que as partes, a partir do momento da propositura da ação, abandonem a litigiosidade e passem a atuar em conjunto até a obtenção da sentença?

O termo "cooperação" autoriza, em tese, tal interpretação, pois equivale a colaborar ou auxiliar. Entretanto, não se pode olvidar o aspecto de que o processo judicial tem sua origem na existência de um conflito de interesses não resolvido e não pacificado ainda pelas partes.

E por conflito entende-se o dissenso, ou contrariedade a expectativas, valores e interesses (VASCONCELOS, 2008, p. 19) das partes que litigam.

Eduardo Ribeiro de Oliveira aponta que, "na doutrina de Carnelutti, considera-se o interesse a posição favorável à satisfação de uma necessidade" (DE OLIVEIRA, 1992, p. 13). Como as necessidades humanas são ilimitadas, e os bens aptos a satisfazê-las, finitos, haverá momentos em que duas (ou mais) pessoas tenham interesses em torno de um mesmo bem. E havendo resistência da pretensão de um dos interessados pelo outro, surgirá então o conflito e a lide.

Uma vez que o Estado, nas sociedades contemporâneas, tem o poder-dever de dizer qual é o direito aplicável a uma determinada situação, e de implementar, ainda que com emprego de força, a solução jurídica indicada, as lides são a ele submetidas, por meio das demandas.

Percebe-se, nessa linha de raciocínio, que o conflito estaria na base do processo judicial, e por sua vez, teria a sua origem na escassez dos bens materiais ou imateriais aptos a satisfazer as necessidades ou interesses dos litigantes.

A inevitabilidade do surgimento do dissenso, aliás, é apontada nas obras de Nietzsche e de Freud: o homem constrói-se pelo conflito. Nesse sentido, Freud aponta que "a opção que se apresenta é aceitar incondicionalmente a vida, com todo sofrimento, conflito e limitações inerentes a ela." (GHISI, 2007, p. 41). 
Mas ainda que admita-se que o conflito esteja na essência da natureza humana, e venha por isso mesmo a se manifestar no trato com os semelhantes, essa ideia de que os conflitos sempre determinam a propositura de demandas judiciais não é compartilhada por todos os autores.

Nesse sentido, os litígios são, no dizer de Boaventura de Sousa Santos, "construções sociais, na medida em que o mesmo padrão de comportamento pode ser considerado litigioso ou não, consoante a sociedade, o grupo social ou o contexto de interações em que ocorre". (SANTOS, 1996).

Assim, ainda que exista no seio da sociedade várias situações de contrariedade a interesses, explicar o surgimento do litígio é extremamente complexo, pois não basta em todo e qualquer caso a lesão a uma dada norma jurídica para dar-lhe nascimento, especialmente quando se pensa nas demandas que buscam apenas uma sentença declaratória, que reconheça uma dada situação de fato ou de direito, apenas para resguardar direitos. Além disso, "todas as sociedades minimamente complexas têm à disposição dos litigantes um conjunto mais ou menos numeroso de mecanismos de resolução dos litígios" (SANTOS, 1996), não necessariamente de ordem judicial.

De fato, o ideal seria que o Direito fosse orientado preferencialmente para a estruturação jurídica eficiente dos objetivos das pessoas, para que eles acontecessem com o menor custo possível de desgaste psicológico, de tempo e de dinheiro, sem a ocorrência de conflitos e sem litígios que fossem resolvidos pela via judicial (Análise Estratégica do Direito). De acordo com essa perspectiva, só por exceção existiriam os conflitos e, caso acontecessem, eles seriam resolvidos preferencialmente por meio de negociação, conciliação, mediação, arbitragem e, apenas de forma excepcional, com a ida das partes aos tribunais, pois, antes de recorrer ao Poder Judiciário, as partes em qualquer litígio deveriam tentar, sempre que possível, resolvê-lo junto às instâncias extrajudiciais, geralmente mais rápidas e mais acessíveis (SANTOS, 1996).

Nessa visão, a ida a um tribunal não decorreria necessariamente do conflito, mas do aspecto de terem falhado a estratégia jurídica desenvolvida pelas partes e todos os outros meios de composição extrajudicial dos eventuais conflitos.

De forma semelhante, Frederico de Andrade Gabrich destaca que a ida aos tribunais decorre de uma visão do Direito, por seus operadores, que ignora o pensar estratégico. Nesse sentido, Gabrich sublinha que:

o pensar estratégico requer, no plano jurídico, a necessidade de encarar o direito como um conjunto de alternativas colocadas à disposição do jurista para a 
estruturação o de empresas negócios e pessoas (físicas e jurídicas, de direito público e de direito privado), de maneira a permitir que os objetivos traçados sejam alcançados com o menor custo possível, como, inclusive, é proposto pela escola da análise econômica do Direito. (...). É fundamental reconhecer o caráter supletivo, subsidiário e verdadeiramente instrumental das disciplinas processuais e do processo (especialmente o judicial), para se atribuir a devida e fundamental importância aos mecanismos de solução extrajudicial dos conflitos, tais como a mediação e a arbitragem. (GABRICH, 2010, p. 16).

Além disso, é fundamental observar também que a atuação estratégica do advogado pode ser absolutamente fundamental para determinar se haverá um conflito e se este irá ou não redundar na propositura de uma ação judicial.

Não obstante, Boaventura de Sousa Santos (1996) menciona que existe no Brasil uma cultura de litigiosidade, que decorre tanto do enfraquecimento dos laços comunitários, dos compromissos de honra e da gestão da vida coletiva, quanto da presença de um número excessivo de advogados. Ademais, segundo o mesmo autor, "a transformação judicial a que é submetido o litígio começa verdadeiramente quando é consultado o advogado e são contratados os seus serviços". (SANTOS, 1996).

Nessa perspectiva, não é desprezível considerar o aspecto de que, pelo menos no Brasil, os advogados tradicionalmente têm formação voltada quase que exclusivamente para o litígio, e não para a estruturação eficiente dos objetivos das pessoas (naturais e jurídicas) ou para a solução extrajudicial e colaborativa de conflitos. Infelizmente, o ensino jurídico está ainda umbilical e preferencialmente ligado à tradição dogmática, positivista e conflituosa, sem a utilização de metodologias ativas e transdisciplinares, capazes de fazer com que os alunos e profissionais do Direito tenham condições efetivas de promover análise crítico-propositiva dos fatos e de pensar em soluções jurídicas estratégicas e sustentáveis para os objetivos das pessoas.

Nesse sentido, Gabrich e Mendonça lamentam que:

com poucas, raras e honrosas exceções, enquanto as pessoas procuram um profissional que saiba antes de tudo ouvir, encontram normalmente "juristas" que somente sabem dizer as suas próprias verdades absolutas e incontestáveis. Enquanto a população geralmente quer a paz, os profissionais do Direito pregam a guerra, por meio de inúmeros "nãos" e infindáveis processos judiciais. Enquanto as pessoas querem estruturar a vida para a felicidade, os profissionais do Direito desconsideram olimpicamente tal interesse e conduzem a atividade profissional para fomentar apenas a luta pelo Direito, sem qualquer preocupação com a pessoa e com a sua dignidade humana. (GABRICH; MENDONÇA, 2010, p.273).

Com todas as questões mencionadas - a origem do processo judicial no conflito, a existência de uma cultura da litigiosidade, e o preparo dos advogados para atuar 
principalmente em processos judiciais -, não deve ser vista com surpresa que uma parte, em uma demanda, veja a outra como adversária ou até mesmo inimiga.

Por isso, quase sempre, as partes e seus advogados estão muito mais preocupados em vencer a "briga", do que estruturar juridicamente uma solução possível e sustentável, que garanta a felicidade e o bem estar das pessoas envolvidas. Daí a preocupação geralmente excessiva das partes em apresentar elementos de convencimento ao Estado Juiz, apenas para reforçar a sua posição de suposta vantagem competitiva em uma disputa, com o enfraquecimento e com a "destruição" dos argumentos da outra parte, sem quase nenhuma preocupação com o contexto e com a solução efetiva e eficiente do conflito.

Em uma relação de tamanha polarização, na prática da vida judicial, dificilmente se esperaria cooperação, mesmo que a lei processual civil a tenha previsto como princípio norteador. Assim, torna-se relevante investigar os limites do princípio da cooperação.

2 Origem do princípio da cooperação

Para entender os limites do princípio da cooperação, é necessário relembrar, primeiro, que há duas formas tradicionais ou modelos de estruturação do processo: o adversarial e o inquisitorial. (DIDIER JÚNIOR, 2011, p. 210).

No primeiro, as partes agem como se estivessem em uma competição ou disputa, e o magistrado porta-se de forma relativamente passiva, pois a sua função é basicamente decidir. Esse modelo de processo preza a individualidade e liberdade das partes, o que leva o juiz para uma posição de coadjuvante.

No segundo modelo, entretanto, o juiz assume posição de protagonismo. Compete ao magistrado o poder da iniciativa probatória, informando quais as questões de fato e direito são importantes para a solução da lide.

Destaca-se que não há ordenamento jurídico em que algum desses dois modelos ocorra de forma exclusiva (BORGES, 2015, p. 32).

Entretanto, surgiu mais recentemente um terceiro modelo, o processo cooperativo, cuja origem se verifica nos ordenamentos jurídicos da Alemanha, França e Portugal (DE FIGUEIREDO, 2017), os quais acabaram por inspirar o legislador brasileiro.

Nesse sentido, considerando o direito processual vigente no Brasil atualmente, Fredie Didier Júnior aponta que

os princípios do devido processo legal, da boa-fé processual e do contraditório, juntos, servem de base para o surgimento de outro princípio do processo: o princípio 
da cooperação. O princípio da cooperação define o modo como o processo civil deve estruturar-se no direito brasileiro. (DIDIER JÚNIOR, 2011, p. 211).

A lei processual civil brasileira não esclarece, entretanto, o que se deve entender por princípio da cooperação, cabendo, assim, aos intérpretes delimitar seu real alcance. E uma tentativa de elucidar seu significado pode partir do esclarecimento daquilo que não ele não é.

Daniel Assumpção, ao tratar sobre o princípio da cooperação, destaca que uma leitura superficial da redação do dispositivo do artigo $6^{\circ}$ do Código de Processo Civil (BRASIL, 2015) dá a impressão falsa de que as partes devem abandonar a defesa de seus interesses e atuar juntas para que seja alcançada a Justiça.

Repelindo tal interpretação, o mencionado autor afirma que "na realidade, a busca da Justiça é tarefa exclusiva do juiz, de forma que as partes devem, dentro dos limites impostos pelo princípio da boa-fé objetiva, tutelar seus interesses contrapostos em juízo" (NEVES, 2017).

Nesse sentido, Eduardo Talamini sublinha que não seria a introdução na redação da lei processual civil do princípio da cooperação, que tornaria o sistema jurídico apto a tornar o processo "um jardim florido em que as partes passeiam de mãos dadas" (TALAMINI, 2018).

Mas não se deve concluir que o princípio tenha sido introduzido já natimorto no ordenamento jurídico brasileiro, em razão da clara disposição de litigância das partes, pois a lei não comporta palavras inúteis.

Assim, em um primeiro aspecto, Didier Jr. menciona que o modelo cooperativo é o mais adequado para a democracia, porque adequado ao modelo constitucional do processo, ao estímulo à participação das partes e ao devido processo legal (DIDIER JÚNIOR, 2011, p. 212). Assim, já se percebe que deveria, de fato, ser buscado pelo legislador um modelo processual diferente do adversarial ou inquisitorial.

Na realidade, o princípio da cooperação, se interpretado e usado adequadamente, pode permitir, no âmbito do processo civil, um verdadeiro "salto ético" a que faz menção Hugo Assmann, quando reconhece que "não somos animais naturalmente solidários para além do círculo bastante limitado aos relacionamentos", e quando aponta que para sairmos dessa posição individualista "precisamos de um salto ético que não costuma suceder espontaneamente. Ele necessita ser alavancado com argumentos, vivências, testemunhos" (ASSMANN, 2000, p. 30). 
O princípio da cooperação se destina, dessa maneira, a transformar o processo em uma ‘comunidade de trabalho' (DIDIER JÚNIOR, p. 2011, p. 216), com clara inspiração no direito português, no qual

coloca-se o órgão jurisdicional como um dos participantes do processo, igualmente gravado pela necessidade de observar o contraditório ao longo de todo o procedimento. O juiz converte-se em um de seus sujeitos. Por força do contraditório, vê-se obrigado ao debate, ao diálogo judiciário. Vê-se na contingência, pois, de dirigir o processo isonomicamente, cooperando com as partes, estando gravado por deveres de esclarecimento, prevenção, consulta e auxílio para com os litigantes. (BORGES, 2015, p. 39)

Sobre essa comunidade de trabalho mencionada por Didier Júnior, Alexandre Câmara Freitas e Antônio Aurélio Abi-Ramia Duarte afirmam que já era incompatíveis om o devido processo legal, antes mesmo da previsão textual da aplicação do princípio da cooperação ao processo civil, a cultura do "jeitinho" e "a deslealdade, a alteração consciente da verdade, a má-fé, entre outros”. E “assim, o processo deve ser o campo de plena e ativa participação de todos os sujeitos do processo (como autêntica comunidade de trabalho), reforçando valores decorrentes do Estado Democrático de Direito". (CÂMARA; DUARTE, 2015, p. 66 e 70)

Marcelo José Magalhães Bonifácio aponta que se observa no princípio da cooperação a tendência de adoção, no processo civil brasileiro, de uma verdadeira ideologia da cooperação.

Entretanto, o mesmo autor é cético quanto à possibilidade de que os litigantes e operadores do Direito venham a tratar o processo de forma radical e ideologicamente diversa da tradição do litígio (BONIFÁCIO, 2016, p. 82).

De qualquer maneira, ainda que se imagine que o princípio da cooperação não seja capaz de induzir uma mudança ideológica ou psicológica nos litigantes e nos seus advogados, não há como olvidar que ele atrai a necessidade de uma alteração comportamental dos demandantes, dos seus advogados, bem como dos magistrados e demais servidores do Poder Judiciário.

3 A cooperação como dever das partes no processo

O princípio da cooperação torna devidos os comportamentos necessários para a obtenção de um processo leal e cooperativo (DIDIER, 2011, p. 213), calcado sobre o agir em conformidade com a boa-fé objetiva. 
Por isso, o Fórum Permanente de Processualistas Civis (FPPC) aprovou, em encontro realizado em novembro de 2013, o enunciado de número 6, segundo o qual o "negócio jurídico processual não pode afastar os deveres inerentes à boa-fé e à cooperação". (DE OLIVEIRA, 2017).

Posteriormente, em maio de 2015, o mesmo órgão aprovou o Enunciado n. 373, que estabelece o seguinte:

as partes devem cooperar entre si; devem atuar com ética e lealdade, agindo de modo a evitar a ocorrência de vícios que extingam o processo sem resolução do mérito e cumprindo com deveres mútuos de esclarecimento e transparência. (DE OLIVEIRA 2017).

Assim, o modelo cooperativo introduzido no Código de Processo Civil (BRASIL, 2015) impõe às partes, e por consequência, aos seus procuradores, atender também aos fundamentos constitucionais da razoabilidade, bem como ao princípio da boa-fé objetiva (o que, inclusive, leva à vedação do uso pelos advogados de argumentos falsos, à ocultação da verdade real e das provas que eventualmente conflitam com os interesses de seus clientes).

Para os magistrados, o modelo impõe uma nova forma de enxergar o contraditório, fomentando uma ampliação de diálogo, para que as partes possam influir significativamente no resultado do julgamento (BONIFÁCIO, 2016, p. 85).

De fato, os deveres de cooperação são elencados ao longo do Código de Processo Civil (BRASIL, 2015), e podem ser divididos em lealdade, esclarecimento, consulta e prevenção.

A lealdade, como já dito decorre da boa-fé, que instruirá a interpretação do pedido (artigo 322, $\S 3^{\circ} \mathrm{CPC}$ ), a decisão judicial (artigo 492, $\S 3^{\circ} \mathrm{CPC}$ ), além da forma de participação de todo aquele que, de qualquer forma, participar do processo (artigo $5^{\circ} \mathrm{CPC}$ ). (BRASIL, 2015).

Assim, todas as partes (e seus procuradores) devem agir com veracidade (artigos 77, I e 80, II CPC), não podem formular pretensão ou apresentar defesa sabidamente destituídas de fundamento (artigo 77, II CPC), não podem criar empecilhos ao cumprimento de ordens judiciais (artigo 77, IV CPC), devem informar o endereço real onde podem ser intimados (artigo 77, V CPC), não podem praticar atos inúteis, contrários a lei ou a fato incontroverso, e não podem promover incidentes temerários (artigo 77, III CPC), ou que importem em inovação ilegal no estado de fato de bem ou direito litigioso (artigo 77, VI CPC) (BRASIL, 2015). 
O dever de esclarecimento, por sua vez, visa a evitar que haja obscuridades que possam induzir erro na decisão de mérito. Expressão dessa obrigação está inserida, inclusive, no disposto no artigo $357, \S 3^{\circ}$, CPC, quando se estabelece o seguinte:

Art. 357. Não ocorrendo nenhuma das hipóteses deste Capítulo, deverá o juiz, em decisão de saneamento e de organização do processo:

...

$\S 3^{\circ}$ Se a causa apresentar complexidade em matéria de fato ou de direito, deverá o juiz designar audiência para que o saneamento seja feito em cooperação com as partes, oportunidade em que o juiz, se for o caso, convidará as partes a integrar ou esclarecer suas alegações. (BRASIL, 2015).

Para exemplificar essa questão, Didier Júnior esclarece, com fundamento no artigo 321 CPC (BRASIL, 2015), que:

\begin{abstract}
se o magistrado estiver em dúvida sobre o preenchimento de um requisito processual de validade, deverá providenciar esclarecimento da parte envolvida, e não determinar imediatamente a consequência prevista em lei para esse ilícito processual (extinção do processo, por exemplo). Do mesmo modo, não deve o magistrado indeferir a petição inicial, tendo em vista a obscuridade do pedido ou da causa de pedir, sem antes pedir esclarecimentos ao demandante - convém lembrar que há hipóteses em que se confere a não-advogados a capacidade de formular pedidos, o que torna ainda mais necessária a observância desse dever. (DIDIER JÚNIOR, 2011, p. 214).
\end{abstract}

Assim, se a petição inicial apresentada pelo autor não se conformar aos requisitos legais da lei processual, cabe a ao magistrado determinar a correção, com a indicação precisa do ponto que merece reparo.

Além disso, o juiz deve proferir decisões e comandos claros, podendo as partes, se necessário, opor embargos declaratórios para afastar obscuridades em quaisquer decisões judiciais, conforme artigo 1.022 CPC (BRASIL, 2015). As partes devem, elas também, promover os seus pronunciamentos com o objetivo de permitir que as decisões judiciais possam ser adequadamente motivadas.

Há o dever de consulta, para evitar a ocorrência de decisões absolutamente surpreendentes no processo. Em decorrência disso, segundo a lei, salvo as exceções admitidas expressamente no ordenamento, e mesmo no caso em que o juiz pode decidir de ofício, "não se proferirá decisão contra uma das partes sem que ela seja previamente ouvida" (artigo $9^{\circ}$, caput CPC). (BRASIL, 2015).

Por isso, sublinha Magalhães Bonifácio que esse diálogo se revela de extrema importância na fase instrutória da demanda, a fim de que seja evitada a produção de provas inúteis, por desconhecimento das partes sobre a opinião do julgador quanto às provas já apresentadas nos autos, ou mesmo a ausência de produção de provas adequadas, o que pode 
redundar na extinção do feito sem o exame do mérito, resultado esse que certamente será decepcionante para um dos litigantes.

Segundo esse autor, "esse diálogo deve nortear todo o processo, embora a fase instrutória pareça ser a mais apropriada para isso, simplesmente porque é nesse momento que surge uma lacuna na relação entre as partes e o juiz quanto à necessidade de produção de provas" (BONIFÁCIO, 2016, p. 87).

Além disso, o juízo tem o dever de manter-se coerente com seus próprios comportamentos, como é mencionado no artigo 926 do CPC, segundo o qual "os tribunais devem uniformizar sua jurisprudência e mantê-la estável, íntegra e coerente" (BRASIL, 2015).

Por fim, ainda dentro dos deveres da cooperação, está o dever de prevenção ou de proteção, mais voltado ao magistrado, e aplicável às situações em que o êxito da ação a favor de qualquer das partes possa ser frustrado pelo uso inadequado do processo (DIDIER JÚNIOR, 2011, p. 216).

Nessa vertente, o juiz tem o dever de auxiliar as partes a superarem obstáculos que dificultem o exercício de suas faculdades processuais, tais como pela explicitação de pedidos pouco claros, pela superação de lacunas na exposição dos motivos dos fatos relevantes debatidos nos autos, pela adequação do pedido à situação concreta e pela sugestão de uma certa atuação pela parte.

É o que se observa, por exemplo, com a determinação da distribuição dinâmica do ônus da prova, pela qual o magistrado determina que produza a prova a parte que melhor esteja habilitada para tanto. Nessa linha, pode o magistrado, ainda, autorizar o alongamento de prazos processuais quando houver dificuldade em atender àquele fixado em lei ou a alteração da ordem de produção de meios de prova (artigo 139, VI CPC) (BRASIL, 2015).

4 O princípio da cooperação, a mediação, a conciliação e a arbitragem

Uma vez que o princípio da cooperação visa a ordenar o comportamento das partes, como já explanado, para dar maior eficácia à solução dos conflitos, além de se obter uma menor duração do tempo do processo e menor dispêndio financeiro para o Estado, não se pode deixar de associá-lo também aos meios de solução consensual dos conflitos, como, por exemplo, a mediação e a conciliação (art. $3^{\circ}, \S^{\circ} \mathrm{CPC}$ ), mesmo no curso do processo (BRASIL, 2015). 
Admite-se, também e na forma da lei, a arbitragem; nessa, além da cooperação das partes perante o juízo arbitral, o legislador afirma que pode ser estabelecida cooperação judiciária, de forma que o órgão do Poder Judiciário venha a determinar o cumprimento de atos determinados pelo juízo arbitral, mesmo os que importarem efetivação de tutela provisória (artigo 237, IV CPC) (BRASIL, 2015).

Trata-se da admissão no processo civil do chamado Sistema Multiportas (Multidoor Courthouse System):

O Fórum de Múltiplas Portas ou Tribunal Multiportas constitui uma forma de organização judiciária na qual o Poder Judiciário funciona como um centro de resolução de disputas, com vários e diversos procedimentos, cada qual com suas vantagens e desvantagens, que devem ser levadas em consideração, no momento da escolha, em função das características específicas de cada conflito e das pessoas nele envolvidas. Em outras palavras, o sistema de uma única 'porta', que é a do processo judicial, é substituído por um sistema composto de vários tipos de procedimento, que integram um 'centro de resolução de disputas', organizado pelo Estado, comporto de pessoas treinadas para receber as partes e direcioná-las ao procedimento mais adequado para o seu tipo de conflito. (LUCHIARI, 2011, p. 308309).

O uso dos meios alternativos de solução de conflitos aponta para uma evolução do Direito, como explicitam Antônio Carlos Diniz Murta e Luiza Farhat Benedito, quando estabelecem que: é preciso encará-lo como a Ciência do "sim" e não mais como sinônimo de conflito.
Imperioso enxergá-lo como a Sabedoria que busca estabelecer alternativas aos
problemas da comunidade, ofertando mecanismo de soluções mais céleres e
efetivos, que resultem numa maior paz, felicidade e satisfação social, como os
mecanismos da mediação, da conciliação e da arbitragem. Evidente, pois, a
necessidade de alteração não apenas dos dogmas tradicionais de ensino do Direito,
mas também das normas, da gestão estatal, do Poder Judiciário e do próprio modelo
mental dominante na esfera jurídica. (BENEDITO; MURTA, 2015).

De fato, são diversas as vantagens da solução consensual de conflitos, tais como, dentre outros: a pacificação social; diminuição significativa de custos financeiros e emocionais; a celeridade; a sensação de controle pelas próprias partes do procedimento, com consequente sensação de satisfação e segurança; e a maior possibilidade de se levar a efeito o acordo realizado, já que as próprias partes o firmaram. (BUZZI, 2017, p. 270).

Nesse sentido, a mediação, a conciliação e a arbitragem surgem, portanto, como estratégias jurídicas que podem utilizadas para atingir o desiderato do princípio da cooperação, que é a obtenção da solução de conflito de forma justa, efetiva, sustentável e em tempo razoável. 


\subsection{Mediação}

Relembra-se, por oportuno, que a mediação é o meio de resolução consensual de conflitos, por meio da qual "um terceiro (mediador), munido de técnicas adequadas, ouvirá as partes e oferecerá diferentes abordagens e enfoques para o problema, aproximando os litigantes e facilitando a composição do litígio.” (DONIZETTI; 2016, p. 125).

A mediação revela-se mais adequada aos casos em que as partes tinham prévio relacionamento (como em conflitos entre familiares e vizinhos), e nela se busca a retomada de diálogo entre as partes, sem que o mediador interfira diretamente para a determinação da solução, uma vez que atua apenas como um facilitador da solução amigável e construída pelas partes.

Por isso, na mediação as partes devem colaborar entre si para chegar a um acordo, provavelmente com concessões mútuas, e para uma efetiva solução para o litígio. Daí a construção da solução pelas partes (em colaboração), e não a imposição de uma decisão pelo mediador. Este não propõe alternativas, apenas intermedeia o diálogo entre as partes.

Conquanto prevista no artigo $3^{\circ}$ do Código de Processo Civil (BRASIL, 2015), a mediação pode ser realizada até mesmo por meio de uma equipe multidisciplinar, já que não está necessariamente relacionada com a interpretação do Direito.

Um dos maiores obstáculos à adoção, de forma mais intensa, dos institutos da conciliação e da mediação pelo Brasil ainda é a resistência em razão da base adversarial, contenciosa, sustentada pela formação acadêmica dos operadores de Direito (GRINOVER, 2008, p. 6), daí se revelando, como anteriormente destacado, necessária a orientação do comportamento das partes pelo princípio da cooperação.

\subsection{Arbitragem}

$\mathrm{Na}$ arbitragem as partes submetem a um terceiro, o árbitro (normalmente um especialista na matéria objeto de disputa), a controvérsia, e esse decide qual a solução a ser implementada no caso concreto.

Vicente Greco diz que "a arbitragem é, pois, um mecanismo que substitui a atuação da jurisdição, entre pessoas maiores de contratar que a escolheram para dirimir litígios relativos a direitos patrimoniais disponíveis." (GRECO FILHO, 2003, p. 337). 
O árbitro e o juiz exercem poderes e atividades assemelhados, e por isso o princípio da cooperação pode (e deve) ser aplicado também no procedimento arbitral.

$\mathrm{Na}$ arbitragem, de uma certa maneira, o princípio da colaboração se revela inclusive legalmente, por exemplo, no duty of disclousure (dever de revelação), previsto no artigo 14, $\S 1^{\circ}$, da Lei n. 9.307/1996 (BRASIL, 1996), e segundo o qual as “pessoas indicadas para funcionar como árbitro têm o dever de revelar, antes da aceitação da função, qualquer fato que denote dúvida justificada quanto à sua imparcialidade e independência”.

Conquanto na arbitragem as partes possam optar pela presença de um árbitro impedido (o que não se adequaria no litígio judicializado ao devido processo legal), devem elas, em razão da boa-fé, serem informadas da presença do possível impedimento.

E como mencionado anteriormente, na arbitragem também existe cooperação entre o Judiciário e poder arbitral, já que não são hierarquicamente subordinados um ao outro. Por isso, se o Judiciário se deparar com um decisão cautelar dada para contrato com cláusula compromissória ou arbitral, recebido por via de Carta Arbitral, deverá colaborar e agir (se provocado) para que a decisão arbitral tenha eficácia plena.

\subsection{Conciliação}

A conciliação, por seu turno, corresponde ao meio de resolução consensual de conflitos em que um terceiro neutro (chamado de conciliador) aproxima as partes e as orienta na construção de um acordo para colocar fim à controvérsia, por vezes sugerindo, ele mesmo, a solução. É vedada, entretanto, na conciliação, o uso de qualquer meio de constrangimento ou intimidação para que as partes conciliem.

De fato, a conciliação revela-se a solução mais adequada quando as partes mantêm uma relação pontual ou mesmo quando não houver vínculo anterior. Por isso, a conciliação é a técnica mais usada quando a controvérsia é travada em torno de questões relacionadas, por exemplo, ao direito do consumidor, porque normalmente não envolve uma relação continuada entre as partes.

O artigo 334, caput, do Código de Processo Civil, prevê a realização de audiência de conciliação antes mesmo de o réu apresentar nos autos a sua defesa, o que indica que as lides devem ser previamente remetidas para a busca de uma solução consensual (objeto de conciliação ou de mediação) antes mesmo de ser proferida a decisão judicial. Nesse sentido, segundo o artigo 334 do CPC: 
Art. 334. Se a petição inicial preencher os requisitos essenciais e não for o caso de improcedência liminar do pedido, o juiz designará audiência de conciliação ou de mediação com antecedência mínima de 30 (trinta) dias, devendo ser citado o réu com pelo menos 20 (vinte) dias de antecedência.

Destaca-se que, neste caso, a ausência de comparecimento das partes previamente intimadas para a audiência, sem justificativa, constitui-se em ato atentatório à dignidade da justiça, sancionável com aplicação de multa (artigo $334, \S 8^{\circ} \mathrm{CPC}$ ), que pode atingir $2 \%$ (dois por cento) do valor da causa (BRASIL, 2015). Percebe-se, assim, a importância dada pelo legislador aos atos processuais que promovam, direta ou indiretamente, inicial ou incidentalmente, a conciliação e/ou a mediação para a solução dos conflitos apresentados em juízo.

Nesse sentido, independentemente da realização dessa audiência, prescreve o artigo 139, V, do CPC, que compete ao magistrado "promover, a qualquer tempo, a autocomposição, preferencialmente com auxílio de conciliadores e mediadores judiciais". (BRASIL, 2015).

Por fim, tem-se a determinação do artigo 165, caput, do CPC, que determina aos tribunais a criação de centros judiciários de solução consensual de conflitos, que passarão a ser responsáveis pela realização dos procedimentos de conciliação e mediação, fomentando, por isso, a autocomposição dos conflitos.

\section{Conclusão}

A despeito da visão tradicional do processo (judicial e/ou administrativo), em que as partes se veem como adversárias, e a cultura de litigiosidade fomentada, em parte, pela formação e pela atuação excessivamente belicosa e principalmente judicial dos advogados, , o Código de Processo Civil consagra em sua redação e em todo o seu contexto o princípio da cooperação.

Como restou demonstrado neste trabalho, esse princípio, cuja gênese está enraizado nos princípios do devido processo legal, da boa-fé processual e do contraditório, visa a orientar o comportamento dos partícipes do processo para que se obtenha, em tempo razoável, decisão de mérito justa, sustentável, equânime e efetiva. O princípio da cooperação está no cerne de um novo modelo de processo, denominado cooperativo, em oposição aos anteriores modelos marcadamente adversariais e inquisitoriais. 
Mesmo que possam restar dúvida entre os autores se o princípio da cooperação poderá, de fato, permitiu ou facilitar uma mudança ideológica e comportamental dos operadores do Direito, não restam dúvidas de que ele estabelece deveres de comportamento colaborativo para as partes, magistrados, promotores e demais servidores, que podem ser reconhecidos mais especificamente nos deveres de lealdade, de esclarecimento, de consulta e de prevenção.

Por isso, como também restou demonstrado, são indissociáveis do princípio da colaboração o uso estratégico do direito para que os objetivos das pessoas sejam estruturados de forma eficiente e sem conflitos, bem como todos os meios consensuais de solução de eventuais conflitos decorrentes dos equívocos da estruturação jurídica promovida pelas pessoas, como são os casos da conciliação, da mediação e da arbitragem, que trazem, a priori, várias vantagens relativamente à solução judicial de conflitos, especialmente em relação à eficiência psicológica promovida por uma solução consensual ou negociada do conflito (nos casos de negociação, conciliação e mediação), bem como geralmente de tempo e de custos gerais de transação (em relação à arbitragem).

Verifica-se, portanto, que o princípio da cooperação pode ser um instrumento normativo realmente eficaz para o enfrentamento do problema desta pesquisa, com o o de soluções mais eficientes para a solução dos conflitos, tanto na esfera judicial, quanto extrajudicial. 


\section{REFERÊNCIAS}

ASSMANN, Hugo; MO SUNG, Jung. Competência e sensibilidade solidária: educar para a esperança. Petrópolis: Vozes, 2000.

BENEDITO, Luiza Machado Farhat; MURTA, Antônio Carlos Diniz. Estratégias jurídicas como forma de repensar o Direito: enfoque no âmbito do Direito Empresarial. I Congresso Nacional do CONPEDI - UFMG/FUMEC/Dom Helder Câmara: 2015. Disponível em: <https://www.conpedi.org.br/publicacoes/66fs1345/h0yx9ly1/8SOB4Bsj7CHVFe39.pdf>. Acesso em: 08 jan. 2018.

BONIFÁCIO, Marcelo José Magalhães. Princípios do processo no novo Código de Processo Civil. São Paulo: Saraiva, 2016.

BORGES, SABRINA GRESSLER. A instrução probatória no novo CPC e os modelos processuais. Disponível em

<http://www.lume.ufrgs.br/bitstream/handle/10183/134581/000987265.pdf?sequence=1 >. Acesso em: 06 jan. 2018.

BRASIL. Constituição da República Federativa do Brasil de 1988. Disponível em: <http://www.planalto.gov.br/ccivil_03/constituicao/constituicaocompilado.htm>. Acesso em: 05 jan. 2018.

BRASIL. Lei n. 9.307, de 23 set. 1996. Dispõe sobre a arbitragem. Disponível em: < http://www.planalto.gov.br/ccivIl_03/Leis/L9307.htm>. Acesso em: 07 jan. 2018.

BRASIL. Lei n. 13.105, de 16 mar. 2015. Disponível em: < http://www.planalto.gov.br/ccivil_03/_ato2015-2018/2015/lei/113105.htm>. Acesso em: 05 jan. 2018.

BUZZI, Marco Aurélio Gastaldi. O princípio da cooperação e a audiência prevista no artigo 334 do Novo Código de Processo Civil. Rio de Janeiro: Revista FONAMEC, v. 1, n. 1, 2017. Disponível em:

<http://www.emerj.tjrj.jus.br/revistas/fonamec/volumes/volumeI/revistafonamec_numero1vol ume1_263.pdf>. Acesso em: 08 jan. 2018.

CÂMARA, Alexandre Freitas; Duarte, Antonio Aurelio Abi-Ramia. O processo como "comunidade de trabalho" e o princípio da cooperação. Revista da EMERJ, Rio de Janeiro, v. 18, n. 70, p. 63-75, set./out. 2015. Disponível em <

https://bdjur.stj.jus.br/jspui/bitstream/2011/96410/processo_comunidade_trabalho_duarte.pdf >. Acesso em: 05 jan. 2018.

DE FIGUEIREDO, Guilherme Assis. O princípio da cooperação no Novo Código de Processo Civil de 2015. Processo, jurisdição e efetividade da justiça III [Recurso eletrônico on-line] organização CONPEDI. Florianópolis: CONPEDI, 2017. Disponível em: <https://www.conpedi.org.br/publicacoes/roj0xn13/1743z27d/1Kbp7ow2ky09Sg6H.pdf>. Acesso em: 05 jan. 2018. 
DE OLIVEIRA, Eduardo Ribeiro. Notas sobre o conceito de lide. São Paulo: Ed. RT, abr.jun. 1992. Disponível em: <

https://www.google.com.br/url?sa=t\&rct=j\&q=\&esrc=s\&source=web\&cd=5\&cad=rja\&uact= 8\&ved=0ahUKEwjZwcG3qMvYAhWLFJAKHenBBFEQFgg5MAQ\&url=https\%3A\%2F\%2 Fbdjur.tjdft.jus.br\%2Fxmlui\%2Fbitstream $\% 2$ Fhandle $\% 2$ Ftjdft $\% 2 F 35130 \% 2 F n o t a s \% 2520$ sob re $\% 2520 \mathrm{o} \% 2520$ conceito $\% 2520 \mathrm{de} \% 2520$ lide.pdf $\% 3$ Fsequence $\% 3 \mathrm{D} 1 \&$ usg $=\mathrm{AOvV}$ aw2pML K2uj7ar9y8jejPeseU>. Consulta em: 05 jan 2018.

DE OLIVEIRA, Pedro Miranda (Org.). Enunciados do Fórum Permanente de Processualistas Civis: Carta de Florianópolis. Disponível em: < http://novoprocessodotrabalho.com.br/uploads/1/0/5/7/105724579/carta_de_florian\%C3\%B3 polis.pdf>. Acesso em: 05 jan. 2018.

DIDIER JÚNIOR, Fredie. Os três modelos de direito processual: inquisitivo, dispositivo e cooperativo. Disponível em: <

https://edisciplinas.usp.br/pluginfile.php/364050/mod_resource/content/0/FREDIE\%20DIDIE R\%20-\%20Os\%20tr\%C3\%AAs\%20modelos\%20de\%20processo\%20-

\%20dispositivo,\%20inquisitivo\%20e\%20cooperativo.pdf $>$. Acesso em: 05 jan. 2018.

DONIZETTI, Elpidio. Princípio da cooperação (ou da colaboração) - arts. $5^{\circ}$ e 10 do projeto do novo CPC. Disponível em: <

https://elpidiodonizetti.jusbrasil.com.br/artigos/121940196/principio-da-cooperacao-ou-dacolaboracao-arts-5-e-10-do-projeto-do-novo-cpc>. Acesso em: 05 jan. 2018.

DONIZETTI, Elpídio. Curso didático de direito processual civil. São Paulo: Atlas, 2016.

GABRICH, Frederico de Andrade (Coord.). Análise estratégica do direito. Belo Horizonte: Universidade FUMEC, 2010.

GABRICH, Frederico de Andrade; MENDONÇA, Rômulo Augusto Lasmar. Análise estratégica do ensino jurídico no Século XXI. Disponível em:<

http://www.publicadireito.com.br/conpedi/manaus/arquivos/anais/sao_paulo/2046.pdf >. Acesso em: 05 jan. 2018.

GUISI, Valéria de Angelo. O homem trágico: Considerações sobre o homem enquanto conflito no primeiro Nietzche e no último Freud. Biblioteca Digital brasileira de Teses e Dissertações: 2007. Disponível em:

<http://www.biblioteca.pucpr.br/tede/tde_busca/arquivo.php?codArquivo=807>. Acesso em: 05 jan. 2018.

GRECO FILHO, Vicente. Direito Processual Civil Brasileiro. $3^{\circ}$ vol. São Paulo: Saraiva, 2003.

GRINOVER, Ada Pellegrini; WATANABE, Kazuo; e NETO, Caetano Lagrasta (coord.). Mediação e Gerenciamento do Processo: guia prático para a instalação do setor de conciliação e mediação. Com Prefácio de Vicenzo Vigoriti. 2. Reimpr. São Paulo: Atlas, 2008 . 
LUCHIARI, Valeria Feriolo Lagrasta. Histórico dos métodos alternativos de solução de conflitos. In: GROSMAN, Claudia Frankel; MANDELBAUM, Helena Gurfinkel (Org.). Mediação no judiciário: teoria na prática. São Paulo: Primavera Editorial, 2011.

NEVES, Daniel Amorim Assumpção. Novo CPC para advogados: Perguntas e respostas para a prática profissional. Rio de Janeiro: Editora Forense. 2017.

SANTOS, Boaventura de Sousa; Marques, Maria Manuel Leitão; PEDROSO, João. Os tribunais nas sociedades contemporâneas. Porto: Afrontamento. 1996. Disponível em: < http://www.anpocs.org.br/portal/publicacoes/rbcs_00_30/rbcs30_07.htm>. Acesso em: 05 jan. 2018.

SENADO FEDERAL. Anteprojeto do Novo Código de Processo civil. Disponível em: < https://www.senado.gov.br/senado/novocpc/pdf/Anteprojeto.pdf $>$. Acesso em: 05 jan. 2018.

TALAMINI, Eduardo. Cooperação no novo CPC (primeira parte): os deveres do juiz. Disponível em: < http://www.migalhas.com.br/dePeso/16,MI226236,41046-

Cooperacao+no+novo+CPC+primeira+parte+os+deveres+do+juiz $>$. Acesso em: 06 jan. 2018.

VASCONCELOS, Carlos Eduardo de. Mediação de conflitos e práticas restaurativas. São Paulo: Método, 2008. 